\title{
Connecting Ears to Eye Muscles: Evolution of a 'Simple' Reflex Arc
}

\author{
Hans Straka ${ }^{a}$ Bernd Fritzsch ${ }^{b}$ Joel C. Glover ${ }^{c}$

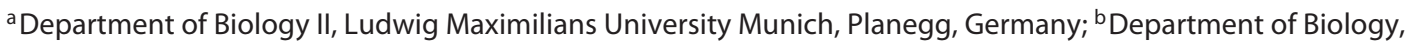 \\ University of lowa, lowa City, lowa, USA; ' Department of Physiology, University of Oslo, Oslo, Norway
}

\section{Key Words}

Ear evolution - Eye muscle evolution - Vestibular nucleus . Vestibular projection - Vestibulo-ocular reflex

\begin{abstract}
Developmental and evolutionary data from vertebrates are beginning to elucidate the origin of the sensorimotor pathway that links gravity and motion detection to image-stabilizing eye movements - the vestibulo-ocular reflex (VOR). Conserved transcription factors coordinate the development of the vertebrate ear into three functional sensory compartments (graviception/translational linear acceleration, angular acceleration and sound perception). These sensory components connect to specific populations of vestibular and auditory projection neurons in the dorsal hindbrain through undetermined molecular mechanisms. In contrast, a molecular basis for the patterning of the vestibular projection neurons is beginning to emerge. These are organized through the actions of rostrocaudally and dorsoventrally restricted transcription factors into a 'hodological mosaic' within which coherent and largely segregated subgroups are specified to project to different targets in the spinal cord and brain stem. A specific set of these regionally diverse vestibular projection neurons functions as the central element that transforms vestibular sensory signals generated by active and passive head and body movements into motor output through the extraocular muscles. The large dynamic range of motion-related sensory signals requires an organi-
\end{abstract}

zation of VOR pathways as parallel, frequency-tuned, hierarchical connections from the sensory periphery to the motor output. We suggest that eyes, ears and functional connections subserving the VOR are vertebrate novelties that evolved into a functionally coherent motor control system in an almost stereotypic organization across vertebrate taxa.

(c) 2014 S. Karger AG, Basel

\section{Introduction}

Almost all extant vertebrates have eyes and ears that are interconnected so that vestibular sensory input can stabilize retinal image motion by guiding coordinated eye movements - the vestibular-ocular reflex (VOR) [Baker, 1998; Fritzsch, 1998; Straka, 2010]. In contrast, neither a vertebrate-like brain nor vertebrate-like eyes or ears exist as specific organs in other chordates [Fritzsch and Glover, 2007] indicating that the entire system that mediates the VOR is a vertebrate novelty. The 'skin-brain' [Fritzsch and Glover, 2007; Pani et al., 2012] of nonvertebrate deuterostomes lacks vestibular neurons, extraocular motoneu-

Abbreviation used in this paper

VOR vestibulo-ocular reflex

\section{KARGER}

E-Mail karger@karger.com

www.karger.com/bbe
(C) 2014 S. Karger AG, Basel

0006-8977/14/0832-0162\$39.50/0
Dr. Joel C. Glover

Department of Physiology, Institute of Basic Medical Sciences University of Oslo

PB 1103 Blindern, NO-0317 Oslo (Norway)

E-Mail joel.glover@medisin.uio.no 
rons, and the lateral eyes and ears found in vertebrates [Fritzsch, 1996; Fritzsch and Glover, 2007] even though molecular data identify sensory precursor cells in deuterostome outgroups of vertebrates [Pierce et al., 2008; Candiani et al., 2011; Vopalensky et al., 2012; Joyce Tang et al., 2013]. While the functional organization of the three-neuron VOR arc that links vestibular sensory organs in the inner ear to eye muscles has long been established [Szentagothai, 1950], it has only recently become apparent how such a complex system of two sensors interconnected by spatially specific neural pathways may have evolved.

Here, we propose that evolution introduced: (1) a set of conserved transcription factors that orchestrate the development of visual and vestibular sensory organ development; (2) an initial direct link from vestibular afferents to extraocular motoneurons; (3) a set of interneurons that relays vestibular signals to the hindbrain/spinal locomotor system; (4) spinal interneurons that relay an efference copy of locomotor output to the extraocular motoneurons to generate compensatory movements of the eyes during self-motion; (5) elaboration of the neck to make the head more movable relative to the body, and (6) a secondary set of interneurons that relays vestibular signals to the extraocular motoneurons, to provide additional compensatory eye movements made necessary by the appearance of less predictable head movements. Accordingly, we suggest that during evolution a simple reflex arc (sensory afferents directly contacting motoneurons) has been transformed into a three-neuron reflex arc (sensory afferents to interneurons to motoneurons) that builds on and supplements an even older eye motion control system that relied on intrinsic spinal locomotor efference copies.

\section{Evolving an Ear and Connecting It to the Hindbrain}

Evolution has recruited specific transcription factors to control the development of specific sensory organs. For example, the Pax gene family of transcription factors apparently evolved with multicellular organisms such as sponges [Hill et al., 2010] and later multiplied into several families associated with the eye and statocyst [Kozmik et al., 2003]. The single Paxb gene apparently evolved into the Pax6 and Pax2/5/8 genes found in all triploblasts. These Pax genes appear to be superorganizers for sensory organ development across phyla, indicating a deep molecular homology of structurally different sensory organs. Whereas Pax6 is uniquely associated with eye development [Gehring, 2011], Pax2/5/8 is related to multiple or- gan systems such as kidney and ear [Bouchard et al., 2010; Christophorou et al., 2010]. While Pax genes are important for ear placode formation and development, additional transcription factors are also required [Chen and Streit, 2013; Fritzsch and Straka, 2014].

The ear of vertebrates is only one of many gravity sensors found in aquatic animals [Markl, 1974; Budelmann, 1988]. Some graviceptors evolved in animals without a central nervous system and thus without the computational capability to integrate multimodal information into appropriate motor outputs. Importantly, none of the deuterostome outgroups of vertebrates have otoconiabearing sensory organs for gravity-dependent orientation, suggesting that the vertebrate otoconia-bearing ear is a novelty within the deuterostome lineage [Fritzsch and Straka, 2014]. However, many deuterostomes have at least cellular precursors that presage the morphological evolution of the vertebrate hair cells [Fritzsch et al., 2007; Burighel et al., 2011; Fritzsch and Straka, 2014]. These primordial and definitive hair cells can be identified not only by their morphological similarities but also by their expression of a unique set of transcription factors and microRNAs [Pierce et al., 2008; Candiani et al., 2011; Joyce Tang et al., 2013]. Experimental evidence suggests that in vertebrates the respective gene products are essential for normal hair cell differentiation [Soukup et al., 2009; Pan et al., 2012]. Thus, the evolution of hair cells likely predates ear evolution, replacing previous hypotheses of ear evolution by a 'hair cell first' hypothesis [Duncan and Fritzsch, 2012; Fritzsch and Straka, 2014]. The 'hair cell first' hypothesis brings into focus the problem of the evolution of the dorsolateral placodes that give rise to ears and lateral line organs. Outgroup comparison suggests that graviceptive otocysts evolved before lateral line-like organs [Budelmann and Bleckmann, 1988]. Therefore, the otic placode can be considered a unique embryonic adaptation that assembles in space and time a cohesive interactive gene network to form ears [Streit, 2007; Grocott et al., 2012].

Comparative data suggest that the first vertebrate ear was primarily a graviceptive statocyst [Budelmann, 1988]. As in mollusks [Budelmann, 1992], angular acceleration detection was likely added later during vertebrate evolution. Graviceptive and angular acceleration sensors evolved into specific morphological patterns distinctively separating jawless from jawed vertebrates [Fritzsch and Straka, 2014]. Jawless vertebrates have either a single torus (hagfish) or two incompletely separated canals (lampreys) [Lewis et al., 1985] combined with a single otoconia-bearing epithelium [Hammond and Whitfield, 2006]. Jawed 
vertebrates have two to three otoconia/otolith-bearing sensory organs for linear translational/graviceptive sensation and three perpendicularly oriented semicircular canals with cristae that detect and vectorially decompose three-dimensional head rotations [Straka and Dieringer, 2004]. The formation of specialized sensors for angular acceleration might have coevolved with an increasingly larger locomotor mobility and the appearance of flexible necks, generating less predictable head movements and/ or the need to resolve ambiguities of otolith organ-mediated tilt/translational acceleration signals during fast locomotion [Angelaki and Cullen, 2008; Lambert et al., 2008]. These eco-physiological alterations during early vertebrate history might have generated the selective pressure to evolve a system for sensing body rotation at high dynamic resolution, including the generation of appropriate eye/head/body-stabilizing motor behaviors.

The transformation of a placode into a complex labyrinth with properly positioned, multiple sensory epithelia depends on many factors [Fritzsch et al., 2007; Chang et al., 2008; Fritzsch and Straka, 2014]. Lamprey and hagfish lack a lateral/horizontal canal and the expression of genes relevant for forming this canal. Experimental manipulation of gene expression can mimic this situation in mammals. For example, Otx 1 and $N-M y c$ null mice have no horizontal semicircular canal [Kopecky et al., 2011], and loss of Foxg1 abolishes horizontal canal crista differentiation [Pauley et al., 2006; Hwang et al., 2009]. Other factors, such as homeobox genes Fgfs and BMPs [Chang et al., 2008], also play a role in this process, and the inner ear shows dramatic malformations or incomplete segregation of sensory epithelia in many mutants, such as the Lmxla null mutation [Nichols et al., 2008]. The emerging picture implies a progressive transformation of a simple ear, as found in jawless vertebrates, through formation of multiple recesses, each associated with its own sensory epithelium, into the complex labyrinth of jawed vertebrates [Fritzsch et al., 2013] paralleled by a concurrent segregation of sensory afferent innervation [de Burlet, 1934; Fritzsch et al., 2002].

Vestibular sensory neurons connecting the hair cells in the sensory epithelia of the labyrinthine end organs to the hindbrain evolved late [Pan et al., 2012]. The parent cell bodies of the vestibular afferent fibers (fig. 1) are located in the ganglion of Scarpa and are somewhat segregated with respect to their peripheral end organs [Fritzsch et al., 2002; Maklad and Fritzsch, 2003b]. Compatible with the necessity for a functional organization of VOR circuitry into separate, frequency-tuned pathways [Straka et al., 2009], vestibular afferent fibers differ in several interrelated morphophysiological properties [Straka and Dieringer, 2004]. Independent of the classification scheme, these neurons form at least two functionally distinct subtypes with different cellular properties, dynamic capabilities and motion-related discharge profiles [Goldberg, 2000; Eatock et al., 2008; Cullen, 2011]. The decomposition and transformation of body motion by semicircular canal and otolith hair cells into electrical signals with different dynamic signatures is maintained at the level of the afferent fibers by connecting hair cells and afferents with matching response properties, illustrating a major functional principle of vestibular signal processing [Straka and Dieringer, 2004; Straka et al., 2009]. Different mechanisms of motion detection make the otolith organs the main origin of the pathway that encodes slow, tonic head/body movements and the semicircular canals the main origin of the pathway that processes fast motion components. Since graviceptive, otolith-like end organs encoding low-dynamic roll and pitch movements are believed to have evolved first, hair cells and afferent fibers with nonadapting response properties likely predominated within the earliest vestibulomotor pathways. The later phylogenetic arrival of semicircular canals along with the necessity to encode rapid angular head acceleration signals and to generate rapid and transient motor reactions provided a high-dynamic detection and sensory encoding system [Goldberg, 2000; Cullen, 2011].

Despite the clear morphophysiological distinction between these low- and high-dynamic vestibular pathways, little is known about the gene-regulatory networks and molecular machinery that specify the ontogenetic differentiation of the respective afferent fiber systems. Only a few factors that influence the development of the differential afferent projection pattern have been identified. For example, the absence of Neurod 1 causes a central intermingling of vestibular and cochlear afferent fibers [Jahan et al., 2010]. Nothing, however, is known about the differential targeting of vestibular afferent subpopulations to the central vestibular projection neuron subgroups related to specific motor outputs [Maklad and Fritzsch, 2003a].

During development, afferent fibers from the different inner ear end organs terminate in a characteristic pattern within the hindbrain (fig. 1a). Developmental segregation of afferents from the different inner ear or lateral line end organs generates precise projections into modality-specific, evolutionarily conserved central target regions [ $\mathrm{Ru}-$ bel and Fritzsch, 2002; Fritzsch et al., 2005; Maklad et al., 2010]. Thus, vestibular afferents terminate on specific central neuronal populations, primarily within the differ- 
Fig. 1. Vestibular end-organ-specific afferent terminations in the vestibular nuclei and monosynaptic labyrinthine afferent signal convergence onto frog central vestibular neurons $\left(2^{\circ} \mathrm{VN}\right)$. a Spatial arrangement of the classical vestibular nuclei on a horizontal section through the dorsal hindbrain $\left(\mathbf{a}_{\mathbf{1}}\right)$ and color-coded overlay of afferent projections from the three semicircular canals $\left(\mathbf{a}_{\mathbf{2}}\right)$ and the three otolith organs $\left(\mathbf{a}_{\mathbf{3}}\right)$ at the same horizontal level as shown in $\mathbf{a}_{\mathbf{1}}$. b Extent of convergence of monosynaptic inputs from one $\left(\mathbf{b}_{1}\right)$, two $\left(\mathbf{b}_{\mathbf{1}}\right)$ or all three $\left(\mathbf{b}_{\mathbf{3}}\right)$ ipsilateral semicircular canals in $2^{\circ} \mathrm{VN}$. c Patterns of otolith-semicircular canal convergence $\left(\mathbf{c}_{\mathbf{1}}, \mathbf{c}_{\mathbf{2}}\right)$ illustrating the proportions of $2^{\circ} \mathrm{VN}$ with monosynaptic responses from one or more end organs, respectively, and the predominant combination of UT and $\mathrm{HC}\left(\mathbf{c}_{\mathbf{1}}\right)$ and of LA and AC or $\mathrm{PC}\left(\mathbf{c}_{\mathbf{2}}\right)$ afferent inputs. $\mathrm{AC} / \mathrm{HC} / \mathrm{PC}=$ Anterior vertical, horizontal, posterior vertical semicircular canal; $\mathrm{CN}=$ cerebellar nucleus; DVN/LVN/MVN/SVN = descending, lateral, medial, superior vestibular nucleus; LA = lagena; SA = saccule; $\mathrm{UT}=$ utricle. $\mathbf{a}$ Illustrations are adopted from Birinyi et al. [2001]. b, c Summaries are based on data from Straka et al. [1997, 2002b].

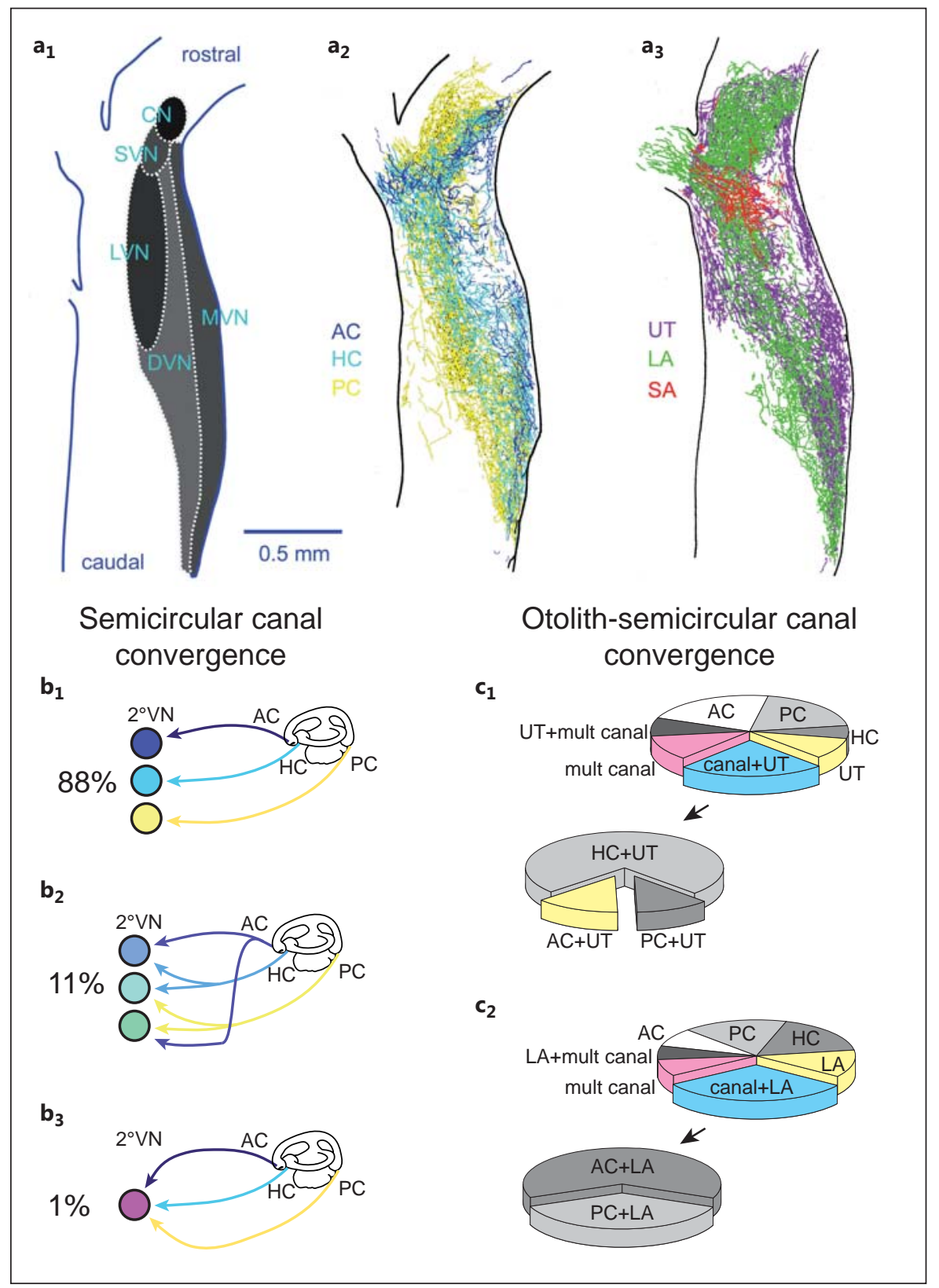

ent vestibular subnuclei (fig. $1 a_{1}$ ). However, despite a differential distribution and moderate spatial segregation, afferent terminations from the different vestibular end organs overlap considerably in all vertebrates (fig. $1 a_{2}, a_{3}$ ) [Maklad and Fritzsch, 2002]. This overlap enables a considerable convergence of information about angular acceleration, concomitant centrifugal force and positional changes in the gravitational field onto individual vestibular neurons [Straka and Dieringer, 2004].

Although afferent projections to the vestibular nuclei [Straka and Dieringer, 2004] and associated polysynaptic circuits [Pflieger and Dubuc, 2004] channeling vestibular information to motoneurons appear to be the principal components of vestibular function in extant vertebrates, there is evidence for a simpler, two-neuron connection within the VOR. In the cat [Uchino et al., 1994, 1996], frog and goldfish [Straka, unpubl. results], a monosynaptic connection from utricular afferents onto ipsilateral abducens motoneurons has been identified anatomically and physiologically. In lampreys, the unusually positioned trochlear motoneurons in the cerebellum [Fritzsch et al., 1990] are very likely to receive direct vestibular afferent 
input [Fritzsch, 1998]. Given the early evolutionary appearance of graviceptive vestibular end organs, this twoneuron reflex arc likely represents the ancestral condition, or a vestige thereof, whereby vestibular afferent information was channeled directly to extraocular motoneurons.

\section{Regionalizing Vestibular Projection Neurons to Define the Flow of Vestibular Information from the Sensory Periphery to the Spinal Cord and to Extraocular Motor Nuclei}

Vertebrate hindbrain development is characterized by segmental patterning at both cellular and genetic levels [Vaage, 1969; Nolte and Krumlauf, 2006]. The hindbrain neuroepithelium in all vertebrates is organized at the gross morphological level into a series of segments, the rhombomeres, which arise by formation of borders within and between earlier prorhombomeric subdivisions [Vaage, 1969; Gilland and Baker, 1993]. Unique combinations of genes encoding transcription factors and cell signaling molecules are expressed in each rhombomeric domain [Nolte and Krumlauf, 2006]. Perpendicular to this rostrocaudal segmentation, the dorsoventral axis becomes subdivided into unique, serial domains of transcription factor expression [Briscoe and Ericson, 2001; Fritzsch and Glover, 2007]. In combination, this patterning of gene expression appears to define the identities and histogenic fates of cells within each rhombomere [Prince et al., 1998; Dasen, 2013; Di Bonito et al., 2013]. Central vestibular neurons that develop within this genetically defined framework become specified into spatially coherent subpopulations with distinct axon projection trajectories and targets [Glover, 2003; Straka, 2010]. Projections from these central vestibular neurons and associated neuronal groups are anatomically and functionally diverse. The main targets are spinal (fig. 2a, c) and extraocular motor nuclei (fig. 2b, c, 3), the cerebellum and hippocampal and thalamic areas [Angelaki and Cullen, 2008].

The diverse sets of vestibular projection neurons are to a large extent spatially parcellated within the segmental and dorsoventral hindbrain scaffold into separate, coherent groups with defined targets (fig. 2). Vestibulospinal projection neurons in fish, frog [Straka et al., 2001], chicken [Glover and Petursdottir, 1991; Díaz et al., 2003] and mouse [Pasqualetti et al., 2007] are known to be nearly completely distinct from those giving rise to vestibuloocular or vestibulocerebellar projections, with only a small subgroup projecting to both spinal and oculomotor targets (fig. 2c) [Straka et al., 2001; Díaz et al., 2003; Díaz and Puelles, 2003]. The specific and remarkably well-conserved segmental and dorsoventral locations of these general groups of vestibular projection neurons suggest a genetic blueprint that was established early in the vertebrate lineage [Glover, 1994; Baker, 1998; Díaz et al., 1998; Glover, 2000; Díaz and Glover, 2002; Straka and Baker, 2013] with possibly minor modifications in lampreys [Fritzsch, 1998].

With regard to distinct axonal trajectories and target regions, vestibulospinal projections derive from 3 separate, coherent groups, one that gives rise to the lateral vestibulospinal tract and 2 that give rise to separate ipsilateral and contralateral components of the medial vestibulospinal tract, respectively (fig. 2a), a pattern that is conserved from frogs to mammals [Glover and Petursdottir, 1991; Suwa et al., 1996; Glover, 2000; Straka et al., 2001; Pasqualetti et al., 2007]. Vestibulo-ocular projections derive from a larger number of groups (fig. $2 b_{1}, b_{2}$ ), each of which can nevertheless be related to specific sets of extraocular motoneuron pools (fig. 3) [Glover, 2000, 2003; Straka et al., 2002a]. Although not absolute, the remarkable degree of spatial segregation exhibited by these coherent projection- and target-defined neuronal groups led to the concept of a 'hodological mosaic' within the vestibular nuclei, a clear indication that the location within the segmental and dorsoventral framework of the

Fig. 2. Regional patterning of vestibular projection neurons according to axon trajectory - the hodological mosaic. a Vestibulospinal projections derive from 3 different neuron populations, the lateral (LVST), the ipsilateral medial (iMVST) and the contralateral medial vestibulospinal tract (cMVST), each originating from a specific segmental and dorsoventral domain, shown here in the chicken embryo $\left(\mathbf{a}_{\mathbf{1}}-\mathbf{a}_{\mathbf{3}}\right)$. $\mathbf{b}$ Vestibulo-ocular projections derive from at least 4 different neuron populations, the ipsilateral rostral (iR-VO), contralateral rostral (cR-VO), ipsilateral caudal (iC-VO) and the contralateral caudal vestibulo-ocular (cC-VO) groups, each originating from a specific hindbrain segmental and dorsoventral domain, shown here in the chicken embryo $\left(\mathbf{b}_{1}, \mathbf{b}_{\mathbf{2}}\right)$. c Segmental and dorsoventral domains of the vestibulospinal, vestibulo-ocular and other vestibular projection neuron types generate a hodological mosaic within the hindbrain with little actual overlap between vestibulo-ocular and vestibulospinal neuron groups in three dimensions. d Comparing the classical vestibular nuclei defined by cytoarchitectonics, the hodological organization of vestibular projections appears as a separate patterning scheme, with a clearer relationship to functional roles, as shown here schematically in the chicken embryo. ang = Nucleus angularis; $d$ = descending vestibular nucleus; Dd = dorsal Deiters' nucleus; Dv = ventral Deiters' nucleus; lam = nucleus laminaris; $\mathrm{m}=$ medial vestibular nucleus; mag = nucleus magnocellularis; $\mathrm{r} 1-\mathrm{r} 11=$ rhombomeres $1-11 ; \mathrm{s}=$ superior vestibular nucleus; $\mathrm{t}=$ tangential vestibular nucleus. $\mathbf{a}$, b, d Illustrations are from Díaz et al. [1998]. c Adapted from Glover [1994, 2003].

(For figure see next page.) 


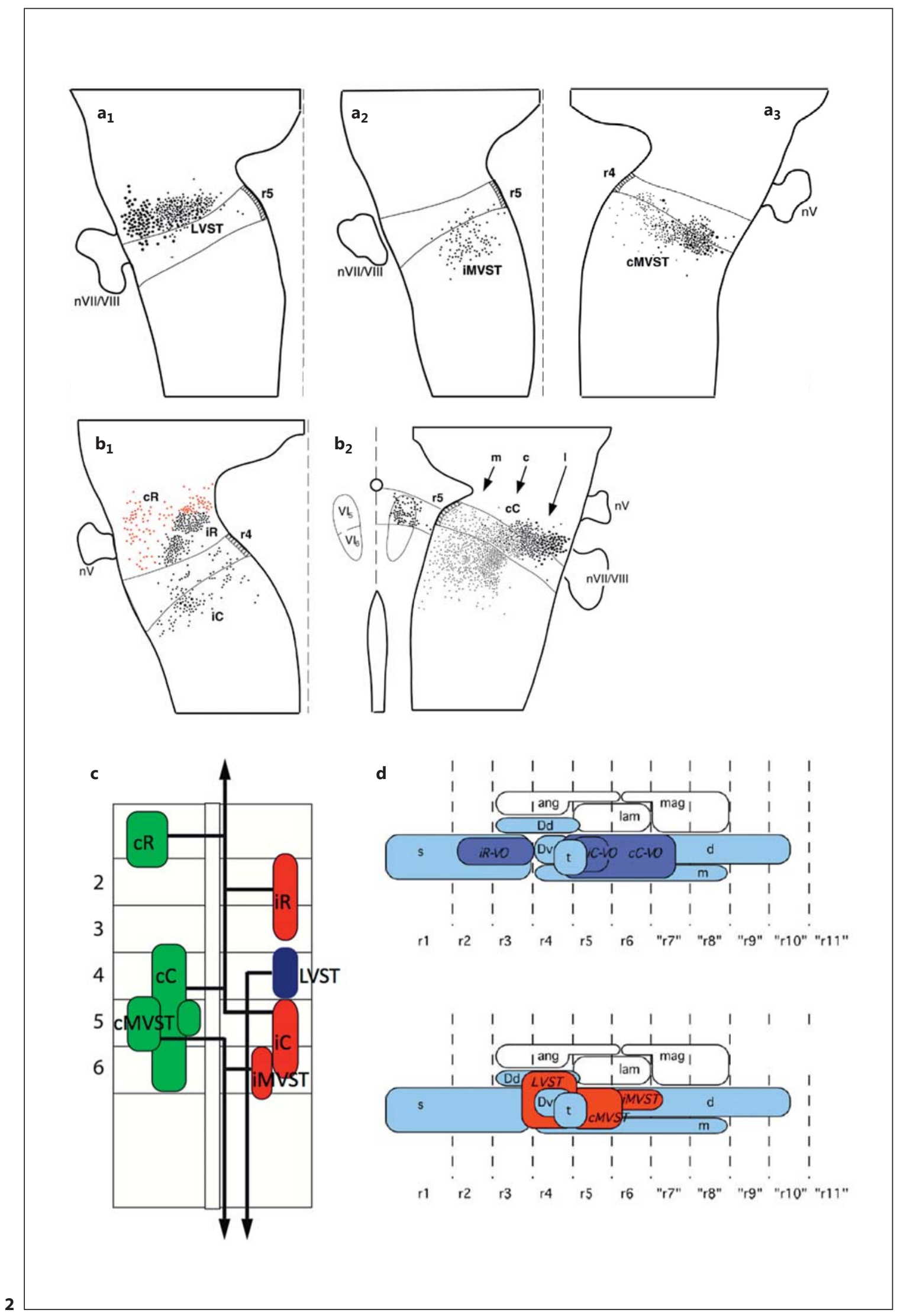


hindbrain is directly linked to the specification of functional phenotypes including synaptic connectivity [Glover, 1994, 2000; Baker, 1998].

A direct comparison of the hodologically defined vestibular projection neuron groups with the classic cytoarchitectonically defined vestibular nuclei (superior, medial, lateral/tangential and descending) in the chicken embryo and frog larva drives home an important point: functional connectivity is more tightly linked to segmental/dorsoventral domains than to cytoarchitectonic domains [Díaz et al., 1998; Cambronero and Puelles, 2000; Straka et al., 2001; Díaz et al., 2003]. Thus, although vestibulo-ocular projections in the classical sense derive from portions of the superior, medial, lateral and descending vestibular nuclei (fig. $1 \mathrm{a}_{1}, 2 \mathrm{~d}$ ), this classification scheme poorly defines the picture because each of these nuclei is a melange of functional subgroups [Díaz et al., 2003; Stra$\mathrm{ka}$ et al., 2005]. The hodological definitions, on the other hand, provide an organizational scheme that not only directly denotes connectivity but also links connectivity to the genetic programs from which it, and likely other functional characters, derive. Thus, studies linking gene expression patterns to connectivity patterns are leading to a reclassification of vestibular anatomy that more clearly reflects the developmental and evolutionary processes responsible for its formation and ultimate function. Indeed, on this hodological backdrop, species-specific variants can be seen that obviously represent selections for or against specific elements of the presumptive vertebrate blueprint [Díaz and Glover, 2002; Pasqualetti et al., 2007; Straka and Baker, 2013].

The highly mosaic topography that relates the different functional subgroups of VOR-related vestibular projection neurons to specific premotor interneuron and motoneuron targets (fig. 3) contrasts with the highly overlapping termination areas of vestibular afferent fibers from the different labyrinthine end organs (fig. $1 a_{2}, a_{3}$ ). Although the absence of an end-organ-specific structured or layered afferent terminal organization in the vestibular nuclei [Birinyi et al., 2001; Straka et al., 2003] suggests a substantial central convergence of inputs from all labyrinthine end organs, this is at variance with the observed functional specificity of central vestibular neurons. In fact, the majority of central vestibular neurons, independent of their position within the hindbrain scaffold, receive monosynaptic afferent inputs from only one semicircular canal (fig. 1b) and/or only one otolith organ [Straka et al., 1997, 2002b]. This means that the vectorial decomposition of angular and linear/graviceptive motion vectors by the different vestibular end organs is essen- tially maintained at the level of the central vestibular neurons. Moreover, when convergence occurs, semicircular canal inputs combine monosynaptically with otolith afferent inputs in an end-organ-specific manner (fig. 1c) [Straka et al., 2002b]. Accordingly, horizontal semicircular canal signals preferentially converge with utricular signals (fig. $1 c_{1}$ ) and vertical semicircular canal signals preferentially converge with signals from vertical otolith organs (fig. $1 c_{2}$; saccule or lagena, depending on the vertebrate taxa) [Straka et al., 2002b].

The specific connections from vestibular afferents to central vestibular neurons might be genetically preprogrammed [Fritzsch et al., 2005; Maklad et al., 2010] or determined retrogradely by the prior established connectivity of vestibular projection neurons with extraocular motoneuron targets [Glover, 2003; Straka, 2010]. Indeed, developmental studies in the chicken embryo show that as soon as synaptic contacts between vestibulo-ocular neurons and extraocular motoneurons are made, there is functional specificity within the VOR circuit spanning from afferents to projection neurons to motoneurons [Glover, 2003; Glover et al., unpubl. data]. The specific semicircular canal and otolith signal convergence (fig. 1c), if not present initially, might be consolidated later using Hebbian plasticity by end organ coactivation during body motion.

Whereas the developmental mechanisms that establish topographically specific VOR connections are beginning to be deciphered, it is less clear how central vestibular neurons with different functional dynamics [Straka et al., 2005] are specified and appropriately inserted into the respective circuits. Compatible with a distinction into frequency-tuned labyrinthine afferent pathways (fig. 4a) [Straka et al., 2009], central vestibular neurons are also subdivided into two major, dynamically different subclasses (fig. $4 \mathrm{~b}_{1}, \mathrm{~b}_{2}$ ) with either low-pass or band-pass filter properties, ideally suited for coding either tonic/lowdynamic or fast, transient head movements (fig. $4 b_{3}$ ) [Straka et al., 2005; Beraneck et al., 2007]. The presence of these dynamically distinct central vestibular neurons with specific intrinsic membrane properties and synaptic response characteristics (fig. $4 \mathrm{~b}$ ) suggests that different head motion components are processed by separate central vestibular networks, as they are by separate peripheral vestibular afferents (fig. 4a) [Straka et al., 2009]. The different dynamic vestibular neuron subclasses do not exhibit obvious preferential regional or segmental distributions, however [Straka et al., 2004]. The developmental mechanisms that link dynamically matched sensory afferents and central projection neurons are unknown, and could involve cell recognition based on intrinsic genetic 


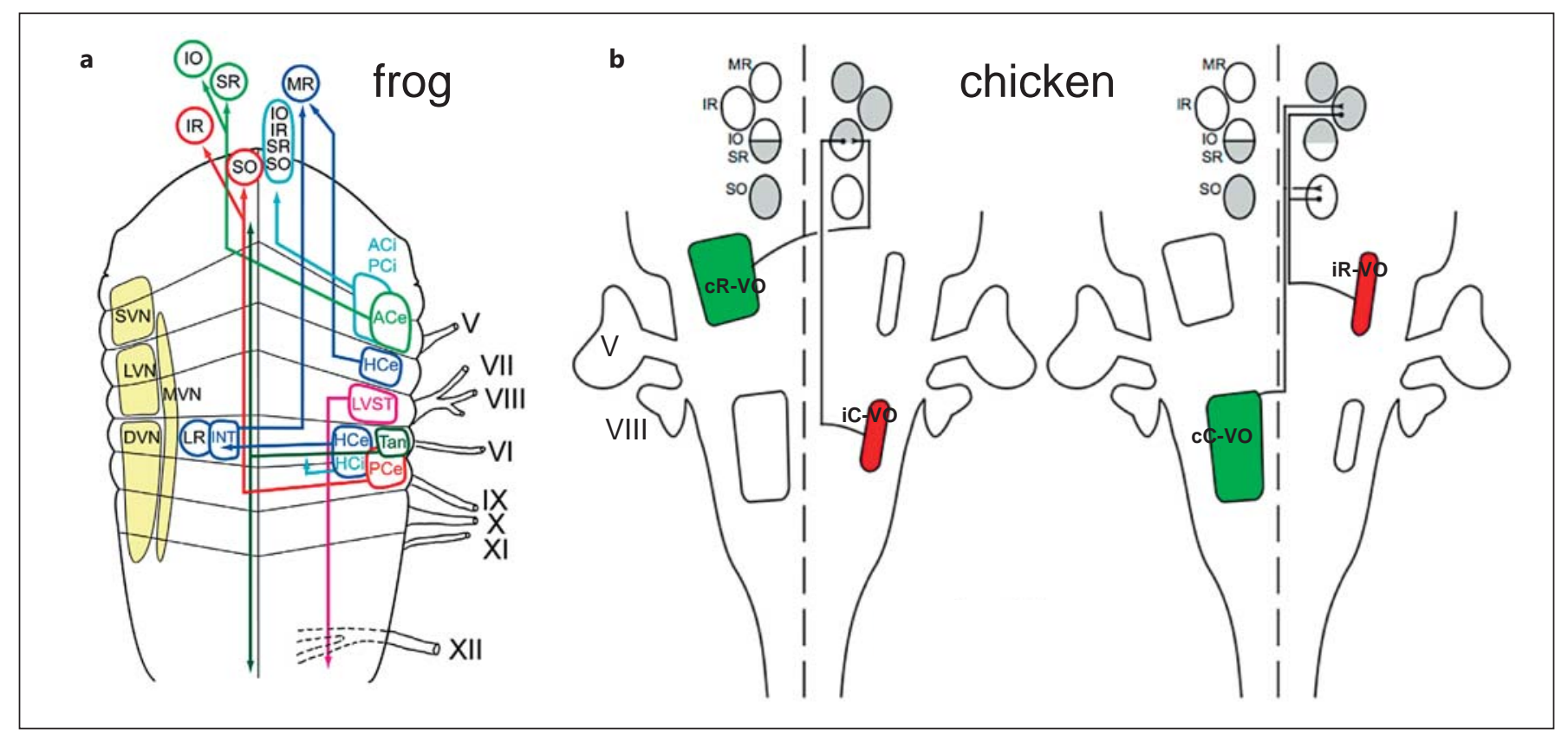

Fig. 3. Hodologically defined VOR projection neurons innervate specific motoneuron pools in a pattern largely conserved from frogs to birds and mammals. a In frogs, VOR projection neurons receiving inputs from specific vestibular sensory end organs project to functionally appropriate extraocular motoneuron pools. Each projection is color coded and labeled according to the peripheral sensory organ and functional effect (e.g. $\mathrm{ACi}=$ anterior canal, inhibitory; $\mathrm{HCe}=$ horizontal canal, excitatory; $\mathrm{PCe}=$ posterior $\mathrm{ca}$ nal, excitatory). DVN/LVN/MVN/SVN = Descending, lateral, medial, superior vestibular nucleus; LR/MR/IR/SR = lateral, medial, inferior, superior rectus motoneurons; $\mathrm{IO} / \mathrm{SO}=$ inferior, superior oblique motoneurons; INT = abducens interneurons. b In the chicken, VOR projection neuron groups exhibit a similar con-

specification, or use-dependent plasticity, whereby dynamically inappropriate synapses are inactivated during development.

\section{Evolving Extraocular Muscles and Ocular Motoneurons}

As is the case for the ear and the eye, extraocular muscles have to be considered a vertebrate novelty. Obviously, non-deuterostomes such as squids [Budelmann and Young, 1993] and copepods [Consi et al., 1987] have eye muscles. However, the most parsimonious interpretation of existing data is that eyes [Lamb, 2013] and extraocular muscles evolved in vertebrates anew among deuterostomes, building on a yet to be determined molecular toolkit of transcription factors. It is now clear that only nectivity pattern. Each group is color coded according to whether it mediates excitatory (green) or inhibitory (red) effects. The cRVO group excites contralateral IO and SR motoneurons, much like the ACe group in the frog. The iC-VO group inhibits ipsilateral IO and SR motoneurons (a similar group has not been described in the frog). The iR-VO group inhibits ipsilateral IR and SO motoneurons, much like the $\mathrm{ACi} / \mathrm{PCi}$ group in frogs. The cC-VO group excites contralateral IR and SO motoneurons, much like the PCe group in frogs. The $\mathrm{cC}-\mathrm{VO}$ group also includes abducens interneurons (INT), which excite contralateral MR motoneurons (not shown for the chicken, but indicated by INT in the frog in a). a Modified from Straka et al. [2002a]. b Adapted from Glover [1994, 2003]. one extant vertebrate, the hagfish, lacks all extraocular muscles and ocular motoneurons [Fritzsch, 1998], whereas all other vertebrates have six extraocular muscles innervated by three discrete cranial nerve nuclei: oculomotor, trochlear and abducens motoneurons. Only limited data exist on the development of extraocular muscles [Wahl et al., 1994], whereas more is known about extraocular motoneurons and their projections [Fritzsch et al., 1995; Ferrario et al., 2012]. Compared to other motoneurons, extraocular motoneurons have unusual properties in terms of susceptibility to disease [Kaminski et al., 2002; Bosley et al., 2006; Tischfield et al., 2010] and molecular specification, such as their unique developmental dependency on the expression of Phox $2 \mathrm{a}$ and Phox $2 \mathrm{~b}$ [Brunet and Pattyn, 2002; Coppola et al., 2005]. This adds to the unusual characteristics of these motoneurons with respect to distribution, migration and axonal projections: 


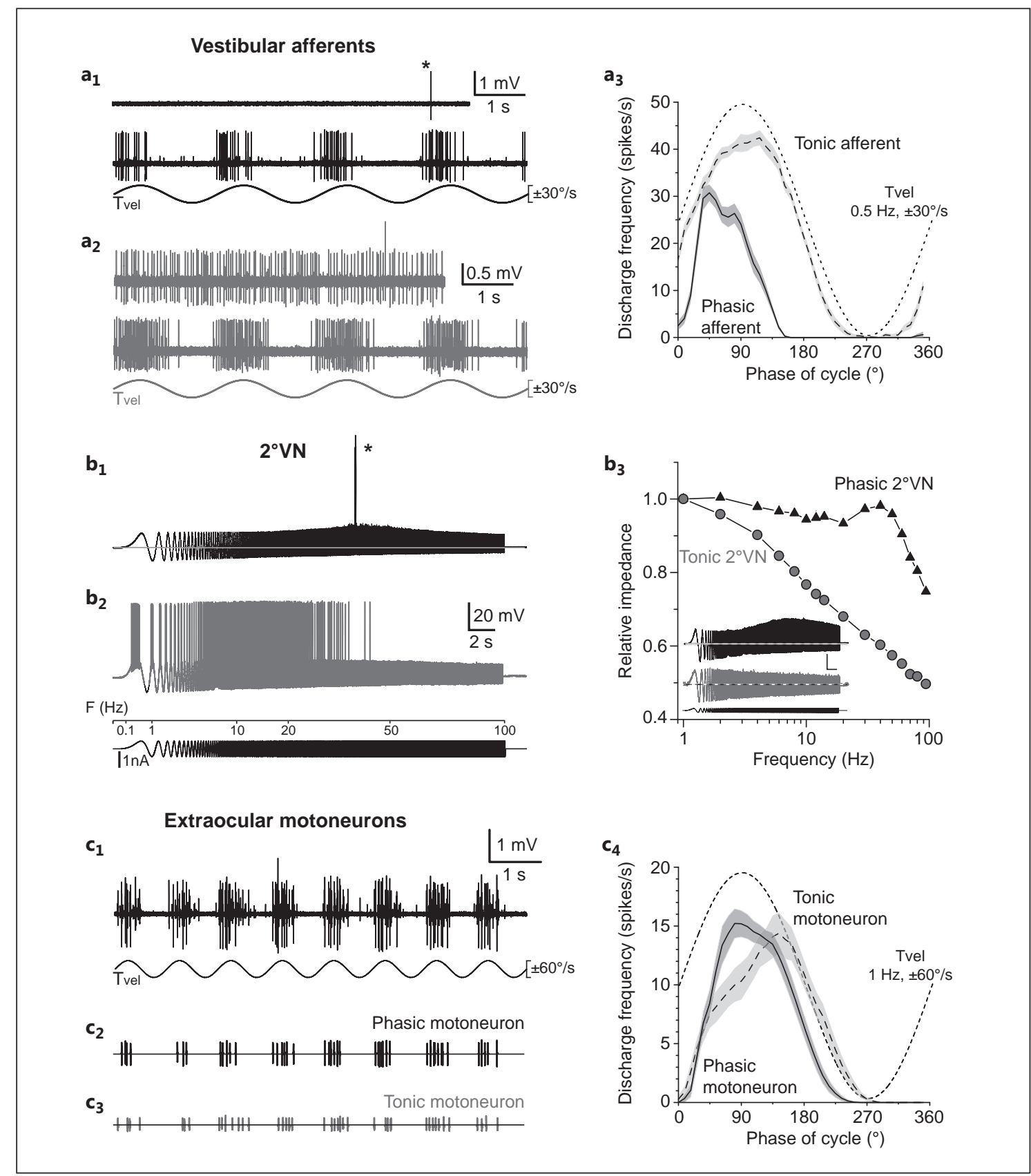

Fig. 4. Differential cellular characteristics of VOR neuronal components in frogs. a Extracellular single-unit recording of phasic $\left(\mathbf{a}_{\mathbf{1}}\right)$ and tonic horizontal semicircular canal afferents $\left(\mathbf{a}_{\mathbf{2}}\right)$; the classification is based on different resting (upper traces in $\mathbf{a}_{\mathbf{1}}, \mathbf{a}_{\mathbf{2}}$ ) and rotation-evoked discharge behavior (lower traces in $\mathbf{a}_{\mathbf{1}}, \mathbf{a}_{\mathbf{2}}$ ); note the low resting firing rate with a single spike in phasic afferents $\left(*\right.$ in $\left.\mathbf{a}_{1}\right)$; peristimulus time histogram $\left(\mathbf{a}_{3}\right)$ of the discharge modulation over one cycle $\left(0-360^{\circ}\right)$ reveals a phase lead of responses in phasic (solid line) and a phase lag of responses in tonic afferents (dashed line) relative to table velocity (Tvel) [Gensberger and Stra$\mathrm{ka}$, unpubl. data]. b Intracellular recordings of phasic $\left(\mathbf{b}_{\mathbf{1}}\right)$ and tonic $\left(\mathbf{b}_{\mathbf{2}}\right)$ central vestibular neurons $\left(2^{\circ} \mathrm{VN}\right)$, identified by different response patterns to sinusoidal current injections; phasic $2^{\circ} \mathrm{VN}$ show single spike synchronization with sine wave current frequencies at $30-50 \mathrm{~Hz}\left({ }^{*}\right.$ in $\left.\mathbf{b}_{\mathbf{1}}\right)$; tonic $2^{\circ} \mathrm{VN}$ discharge at low frequencies and stop firing above $50 \mathrm{~Hz}$; subthreshold impedance profiles of phasic $\left(\mathbf{b}_{3}\right.$, black trace in inset) and tonic $2^{\circ} \mathrm{VN}\left(\mathbf{b}_{\mathbf{3}}\right.$, gray trace in inset) corroborate respective functions as band-pass and low-pass filters; data adopted from Beraneck et al. [2007]. c Extracellular multiple-unit discharge recording of the abducens nerve during vertical-axis rotation $\left(\mathbf{c}_{1}\right)$; spike-shape analysis separated phasic $\left(\mathbf{c}_{\mathbf{2}}\right)$ from tonic motoneurons $\left(\mathbf{c}_{\mathbf{3}}\right)$; peristimulus time histogram $\left(\mathbf{c}_{\mathbf{4}}\right)$ of the discharge modulation over one cycle $\left(0-360^{\circ}\right)$ reveals a phase lead of responses in phasic (solid line) and a phase lag of responses in tonic motoneurons (dashed line) relative to table velocity (Tvel) [Dietrich and Straka, unpubl. data]. 
- Oculomotor motoneurons are the only motoneuron population of which a subset migrates across the floor plate to the contralateral side, thus causing it to innervate the contralateral superior rectus muscle in all vertebrates [Puelles, 1978; Fritzsch and Northcutt, 1993b; Fritzsch et al., 1995].

- Trochlear motoneurons are the only motoneurons that have a dorsal exit to reach the contralateral superior oblique muscle [Fritzsch and Northcutt, 1993].

- Abducens motoneurons are the only hindbrain motoneurons that exhibit phyletic differences in the exit of their axons, ranging from sharing the trigeminal nerve root to having an independent ventral exit with variable segmental positions of the somata ( $\mathrm{r} 4$ to $\mathrm{r} 6 \mathrm{in}$ lampreys [Fritzsch, 1998; Murakami et al., 2004]; r5 and r6 in teleosts, reptiles and birds; $r 6$ in elasmobranchs [Gilland and Baker, 1993, 2005], and r5 in mammals and anurans [Fritzsch and Nichols, 1993; Straka et al., 2002a]).

Beyond these molecular and anatomical peculiarities, motoneuron innervation of the six extraocular muscles shows only two distinct patterns: the lamprey pattern and the jawed vertebrate pattern [Fritzsch et al., 1990]. The lamprey pattern is characterized by three extraocular muscles innervated by the oculomotor, one by the trochlear and two by the abducens nerve. In contrast, all jawed vertebrates have four extraocular muscles innervated by the oculomotor, one by the trochlear and one by the abducens nerve. Many vertebrates also have a seventh eye muscle that functions variably to retract the eye bulb or to close the eyelid. This extra muscle is innervated by motoneurons located in the proximity of lateral rectus (abducens) motoneurons with axons that exit the hindbrain with the abducens nerve [Gilland and Baker, 2005]. In principle, there are two possibilities to explain these differences. One is that the lamprey displays the original configuration, and jawed vertebrates express the derived condition, characterized by relegating one eye muscle innervated by the abducens nerve to function as a retractor and at least one oculomotor nerve-innervated muscle splitting to form an additional extraocular muscle [Fritzsch, 1998]. However, given that lampreys and hagfish are now considered to be sister taxa [Rota-Stabelli et al., 2011], the lack of extraocular muscles and their innervation in hagfish must be considered as derived. Assuming a secondary loss of extraocular muscles in hagfish, the other possibility is that the last common ancestor of lampreys, hagfish and jawed vertebrates had seven extraocular muscles innervated in a pattern that combines the conditions found in lampreys and jawed vertebrates [Puzdrowski, 1998]. In contrast to this plausible construct, fossil data suggest that stem groups of jawed vertebrates had the lamprey eye muscle pattern [Young, 2008].

Regardless of the particular evolutionary scenario that led to the establishment of the VOR, all pools of extraocular motoneurons have to be contacted by spatially and dynamically adequate sets of VOR projection neurons to ensure appropriate reflex function [Lorente de Nó, 1933; Szentagothai, 1950; Straka and Dieringer, 2004]. Compatible with the idea of VOR pathways as frequencytuned channels [Straka et al., 2009], the presence of dynamically different subtypes of vestibular afferents (fig. 4a) and VOR-related projection neurons (fig. $4 \mathrm{~b}$ ) is matched by a similar division of extraocular motoneurons into two subgroups with discharge behaviors suitable for coding low- (fig. $4 c_{1}-c_{3}$ ) and high-dynamic signals (fig. $4 \mathrm{c}_{1}, \mathrm{c}_{2}$ ), innervating muscle fibers with matching properties [Straka and Dieringer, 2004]. Developmental studies indicate that VOR projection neurons establish synaptic connections with the respective pools of extraocular motoneurons before the onset of sensory function [Glover, 2003; Straka, 2010]. This suggests a formation of appropriate connections between VOR projection neurons and extraocular motoneurons guided by molecular markers, potentially depending on prior connectivity between motoneurons and target eye muscles [Glover, 2003].

\section{Evolving the VOR as an Integrative Transformation of Body Movements into Eye Movements}

Based on the presumed phylogenetic precedence of otolith organ-derived to semicircular canal-derived vestibular reflexes, VOR circuits mediating low-dynamic head motion signals likely appeared before those mediating high-dynamic head motion signals. In both types of circuits, central vestibular neurons represent a center for integrating multimodal motion-related signals and a convenient substrate for plastic modification of the sensorymotor transformation [Straka and Dieringer, 2004]. The activation of a dynamic VOR during self-motion, however, is not sufficient for effective retinal image motion stabilization, in particular in animals that have a foveated retina. Visual feedback signals representing residual retinal image slip are also required. Accordingly, signals activated by large-field image motion and mediated by optokinetic circuits in the pretectum converge with vestibular signals immediately at the level of the extraocular motoneurons [Cochran et al., 1984] or are transmitted 
indirectly through olivary and cerebellar pathways. The matching specificity of the directionally partitioned optokinetic system and the three semicircular canals [Simpson and Graf, 1985] is either a coincidence related to an optimal coding strategy for vectorial decomposition of $3 \mathrm{D}$ motion in space, or evidence for an organizational influence of an earlier evolving visual motion detection system on the spatial arrangement of a later evolving labyrinthine sensory system. Irrespective of the actual evolutionary interactions between the two systems, precise genetic regulation during ontogeny is necessary to generate an optimal visuovestibulo-motor circuitry for the stabilization of retinal image motion.

Although transformation of visuovestibular sensory signals into extraocular motor commands has long been considered to be the exclusive mechanism for gaze stabilization [Angelaki and Cullen, 2008], spinal central pattern generator-derived efference copies have recently been shown to directly elicit compensatory eye movements during locomotion in Xenopus without involvement of sensory feedback [Combes et al., 2008; Lambert et al., 2012]. These nonsensory, intrinsic feed-forward commands, however, do not combine additively with vestibular signals but actively suppress the horizontal semicircular canal-derived angular VOR [Lambert et al., 2012]. The implementation of such a signaling pathway also in adult frogs with limb-based locomotion [von Uckermann et al., 2013] suggests that it is a general vertebrate property and independent of locomotor strategy. Furthermore, the role of locomotor efference copy signals in image motion stabilization might be representative of an ancestral condition in early vertebrates before the formation of specific inner ear organs for the detection and encoding of oscillatory horizontal head rotations during undulatory swimming. The ubiquitous availability of locomotor efference copy during rhythmic tail-based swimming already in early tadpole-like chordate ancestors [Fetcho, 1992; Wada, 1998] and its potential recruitment for other motor tasks, including eye movements, might have reduced the evolutionary selective pressure for developing a specific sensory organ in the inner ear for horizontal motion detection [Lambert et al., 2012]. Until the relatively late formation of horizontal semicircular canals through a recruitment of the Foxg1 gene in jawless [Pauley et al., 2006] and the Otxl gene in jawed vertebrates [Mazan et al., 2000; Fritzsch et al., 2001], spatiodynamically appropriate, image-stabilizing eye movements could have been elicited exclusively by intrinsic locomotor efference copies during tail-based locomotion in aquatic vertebrate ancestors.
Increased locomotor speed and performance, development of more flexible necks and other morphological adaptations that significantly reduced the predictability of head motion based on locomotor profiles [Chagnaud et al., 2012] or the appearance of limbs with head-attached muscles that increased the occurrence of unpredictable motion of the head [Trinajstic et al., 2013] could have driven the development of a specific sensory feedback system to detect head motion in space independent of body motion. The presence of a retinal image motionstabilizing mechanism that relies exclusively on intrinsic locomotor signals, independent of motion-sensing balance organs [Lambert et al., 2012], is compatible with the idea that eyes and extraocular muscles appeared before the horizontal duct system of the inner ear. Once an intrinsic efference copy-dependent mechanism for gaze stabilization had evolved, it was likely retained throughout vertebrate evolution. It is thus probable that efference copies also access gaze control centers in vertebrates that are confronted with more complex visual disturbances resulting from flexible necks and limb-based locomotor strategies.

\section{Conclusions}

During evolution, the inner ear was transformed from a simple torus with three distinct sensory epithelia into a labyrinth consisting of three canals and two/three otolith organs, each with a separate associated sensory epithelium. These peripheral sensors connect to the hindbrain through sensory afferents, which terminate on two types of neuronal targets, extraocular motoneurons and premotor vestibular projection neurons. They thus exhibit at least vestiges of the likely ancestral two-neuron reflex arc as well as the extant three-neuron VOR arc that targets the afferents, in a partially overlapping yet spatially specific pattern, onto subpopulations of vestibular projection neurons. This convergence onto an intermediate layer of interneurons allows an integration of signals encoding changes of head/body position in the gravitational field with those related to angular acceleration or to neck/ limb proprioception, creating in addition the capacity for adaptive plasticity of visuovestibular signals to changing ecophysiological contexts. VOR projection neurons with different output connections originate from specific segmental and dorsoventral locations within the hindbrain rhombomeric scaffold. This relationship links gene expression directly to functional connectivity, thus generating the 'hodological mosaic' organization that represents 
an evolutionarily conserved bauplan with species-specific variations. It also indicates the implementation of a topographic principle of central vestibular organization based on motor output rather than sensory input, and thus a particularly important role of prior extraocular motoneuron development on the specificity of VOR projections. The spatial specificity of these connections is complemented by a matching dynamic specificity at hierarchal levels, illustrating the functional principle of frequency-tuned neuronal channels.

Whereas extraocular motoneurons are relatively well conserved, the specific positions of eye muscles in the orbit and their innervation patterns differ taxonomically, and in jawed vertebrates they are associated with the evolution of the lateral/horizontal semicircular canal. The late evolutionary arrival of this canal is surprising given the large horizontal head movements that almost certainly occurred during swimming in vertebrate ancestors. A likely explanation is that compensatory lateral eye movements were originally activated by intrinsic locomotor efference copies in early aquatic vertebrates. Since vertebrates even- tually evolved limbs and the ability to move the head independently of the body, an additional component of the sensory system was required to monitor more complex head movements to generate appropriate extraocular motor commands for retinal image stabilization.

\section{Acknowledgments}

B.F. was supported by a NASA ISGC Base Program and an NIDCD P30 grant. H.S. was supported by the German Science Foundation (CRC 870, TP B12). J.C.G. was supported by the Norwegian Research Council and the University of Oslo. H.S. and J.C.G. shared a grant from the German Academic Exchange Service (DAAD). This paper is based on the authors' invited contributions to the 7th European Conference on Comparative Neurobiology in Budapest, April 2013. We wish to thank the organizers for the invitation.

\section{Disclosure Statement}

The authors report no conflicting interests.

\section{References}

Angelaki DE, Cullen KE (2008): Vestibular system: the many facets of a multimodal sense. Annu Rev Neurosci 31:125-150.

- Baker R (1998): From genes to behavior in the vestibular system. Otolaryngol Head Neck Surg 119:263-275.

Beraneck M, Pfanzelt S, Vassias I, Rohregger M, Vibert N, Vidal P, Moore L, Straka H (2007): Differential intrinsic response dynamics determine synaptic signal processing in frog vestibular neurons. J Neurosci 27:4283-4296.

- Birinyi A, Straka H, Matesz C, Dieringer N (2001): Location of dye-coupled second order and of efferent vestibular neurons labeled from individual semicircular canal or otolith organs in the frog. Brain Res Bull 921:44-59.

Bosley TM, Oystreck DT, Robertson RL, al Awad A, Abu-Amero K, Engle EC (2006): Neurological features of congenital fibrosis of the extraocular muscles type 2 with mutations in PHOX2A. Brain 129:2363-2374.

Bouchard M, de Caprona D, Busslinger M, Xu P, Fritzsch B (2010): Pax2 and Pax8 cooperate in mouse inner ear morphogenesis and innervation. BMC Dev Biol 10:89.

Briscoe J, Ericson J (2001): Specification of neuronal fates in the ventral neural tube. Curr Opin Neurobiol 11:43-49.

Brunet JF, Pattyn A (2002): Phox2 genes - from patterning to connectivity. Curr Opin Genet Dev 12:435-440.

- Budelmann BU (1988): Morphological diversity of equilibrium receptor systems in aquatic in- vertebrates; in Atema J, Fay RR, Popper Chang W, Lin Z, Kulessa H, Hebert J, Hogan BL, AN, Tavolga WN (eds): Sensory Biology of Aquatic Animals. New York, Springer, pp 757-782.

Budelmann B (1992): Hearing in nonarthropod invertebrates; in Webster DB, Fay RR, Popper AN (eds): The Evolutionary Biology of Hearing. New York, Springer, pp 141-155.

- Budelmann BU, Bleckmann H (1988): A lateral line analogue in cephalopods: water waves generate microphonic potentials in the epidermal head lines of Sepia and Lolliguncula. J Comp Physiol A 164:1-5.

Budelmann BU, Young JZ (1993): The oculomotor system of decapod cephalopods: eye muscles, eye muscle nerves, and the oculomotor neurons in the central nervous system. Philos Trans R Soc Lond B Biol Sci 340:93-125.

Burighel P, Caicci F, Manni L (2011): Hair cells in non-vertebrate models: lower chordates and molluscs. Hear Res 273:14-24.

Cambronero F, Puelles L (2000): Rostrocaudal nuclear relationships in the avian medulla oblongata: a fate map with quail chick chimeras. J Comp Neurol 427:522-545.

Candiani S, Moronti L, De Pietri Tonelli D, Garbarino G, Pestarino M (2011): A study of neural-related microRNAs in the developing amphioxus. Evodevo 2:15.

Chagnaud BP, Simmers J, Straka H (2012): Predictability of visual perturbation during locomotion: implications for corrective efference copy signaling. Biol Cybern 106:669-679. $\mathrm{Wu}$ DK (2008): Bmp4 is essential for the formation of the vestibular apparatus that detects angular head movements. PLoS Genet 4:e1000050

Chen J, Streit A (2013): Induction of the inner ear: stepwise specification of otic fate from multipotent progenitors. Hear Res 297:3-12.

Christophorou NA, Mende M, Lleras-Forero L, Grocott T, Streit A (2010): Pax2 coordinates epithelial morphogenesis and cell fate in the inner ear. Dev Biol 345:180-190.

- Cochran SL, Dieringer N, Precht W (1984): Basic optokinetic-ocular reflex pathways in the frog. J Neurosci 4:43-57.

Combes D, Le Ray D, Lambert FM, Simmers J, Straka H (2008): An intrinsic feed-forward mechanism for vertebrate gaze stabilization. Curr Biol 18:241-243.

Consi TR, Macagno ER, Necles N (1987): The oculomotor system of Daphnia magna. The eye muscles and their motor neurons. Cell Tissue Res 247:515-523.

Coppola E, Pattyn A, Guthrie SC, Goridis C, Studer M (2005): Reciprocal gene replacements reveal unique functions for Phox2 genes during neural differentiation. EMBO J 24:43924403.

Cullen K (2011): The neural encoding of self-motion. Curr Opin Neurobiol 21:587-595.

Dasen J (2013): Hox genes: choreographers in neural development, architects of circuit organization. Neuron 80:12-34. 
de Burlet HM (1934): Vergleichende Anatomie des statoakustischen Organs. a) Die innere Ohrsphäre; in Bolk L, Göppert E, Kallius E, Lubosch W (eds): Handbuch der vergleichenden Anatomie der Wirbeltiere. Berlin, Urban \& Schwarzenberg, vol 2, pp 1293-1432.

Di Bonito M, Glover JC, Studer M (2013): Hox genes and region-specific sensorimotor circuit formation in the hindbrain and spinal cord. Dev Dyn 242:1348-1368.

Díaz C, Glover JC (2002): Comparative aspects of the hodological organization of the vestibular nuclear complex and related neuron populations. Brain Res Bull 57:307-312.

-Díaz C, Glover JC, Puelles L, Bjaalie J (2003): The relationship between hodological and cytoarchitectonic organization in the vestibular complex of the 11-day chicken embryo. J Comp Neurol 457:87-105.

Díaz C, Puelles L (2003): Plurisegmental vestibulocerebellar projections and other hindbrain cerebellar afferents in midterm chick embryos: biotinylated dextranamine experiments in vitro. Neuroscience 117:71-82.

Díaz C, Puelles L, Marin F, Glover JC (1998): The relationship between rhombomeres and vestibular neuron populations as assessed in quail-chick chimeras. Dev Biol 202:14-28.

Duncan JS, Fritzsch B (2012): Evolution of sound and balance perception: innovations that aggregate single hair cells into the ear and transform a gravistatic sensor into the organ of Corti. Anat Rec (Hoboken) 295:1760-1774.

Eatock RA, Xue J, Kalluri R (2008): Ion channels in mammalian vestibular afferents may set regularity of firing. J Exp Biol 211:1764-1774.

-Ferrario JE, Baskaran P, Clark C, Hendry A, Lerner O, Hintze M, Allen J, Chilton JK, Guthrie SC (2012): Axon guidance in the developing ocular motor system and Duane retraction syndrome depends on Semaphorin signaling via alpha2-chimaerin. Proc Natl Acad Sci USA 109:14669-14674

Fetcho JR (1992): The spinal motor system in early vertebrates and some of its evolutionary changes. Brain Behav Evol 40:82-97.

Fritzsch B (1996): Similarities and differences in lancelet and craniate nervous systems. Isr J Zool 42:147-160.

Fritzsch B (1998): Evolution of the vestibulo-ocular system. Otolaryngol Head Neck Surg 119: 182-192.

-Fritzsch B, Beisel KW, Jones K, Farinas I, Maklad A, Lee J, Reichardt LF (2002): Development and evolution of inner ear sensory epithelia and their innervation. J Neurobiol 53:143-156.

-Fritzsch B, Beisel KW, Pauley S, Soukup G (2007): Molecular evolution of the vertebrate mechanosensory cell and ear. Int J Dev Biol 51:663-678.

Fritzsch B, Glover JC (2007): Evolution of the deuterostome central nervous system: an intercalation of developmental patterning processes with cellular specification processes; in Kaas JH (ed): Evolution of Nervous Systems. Oxford, Academic Press, vol 2, pp 1-24.

Fritzsch B, Gregory D, Rosa-Molinar E (2005): The development of the hindbrain afferent projections in the axolotl: evidence for timing as a specific mechanism of afferent fiber sorting. Zoology (Jena) 108:297-306.

-Fritzsch B, Nichols DH (1993): DiI reveals a prenatal arrival of efferents at the differentiating otocyst of mice. Hear Res 65:51-60.

Fritzsch B, Nichols DH, Echelard Y, McMahon AP (1995): Development of midbrain and anterior hindbrain ocular motoneurons in normal and Wnt-1 knockout mice. J Neurobiol 27:457-469.

Fritzsch B, Northcutt RG (1993a): Cranial and spinal nerve organization in amphioxus and lampreys: evidence for an ancestral craniate pattern. Acta Anat (Basel) 148:96-109.

Fritzsch B, Northcutt RG (1993b): Origin and migration of trochlear, oculomotor and abducent motor neurons in Petromyzon marinus L. Brain Res Dev Brain Res 74:122-126.

Fritzsch B, Pan N, Jahan I, Duncan JS, Kopecky BJ, Elliott KL, Kersigo J, Yang T (2013): Evolution and development of the tetrapod auditory system: an organ of Corti-centric perspective. Evol Dev 15:63-79.

Fritzsch B, Sonntag R, Dubuc R, Ohta Y, Grillner $S$ (1990): Organization of the six motor nuclei innervating the ocular muscles in lamprey. J Comp Neurol 294:491-506.

Fritzsch B, Signore M, Simeone A (2001): Otx1 null mutant mice show partial segregation of sensory epithelia comparable to lamprey ears. Dev Genes Evol 211:388-396.

Fritzsch B, Straka H (2014): Evolution of mechanosensory hair cells and inner ears: toward identifying stimuli that select mutation driven altered morphologies. J Comp Physiol A Neuroethol Sens Neural Behav Physiol 200: 5-18.

Gehring WJ (2011): Chance and necessity in eye evolution. Genome Biol Evol 3:1053-1066.

Gilland E, Baker R (1993): Conservation of neuroepithelial and mesodermal segments in the embryonic vertebrate head. Acta Anat (Basel) 148:110-123.

Gilland E, Baker R (2005): Evolutionary patterns of cranial nerve efferent nuclei in vertebrates. Brain Behav Evol 66:234-254.

Glover JC (1994): The organization of vestibuloocular and vestibulospinal projections in the chicken embryo. Eur J Morphol 32:193-200.

-Glover JC (2000): Neuroepithelial 'compartments' and the specification of vestibular projections. Prog Brain Res 124:3-21.

Glover JC (2003): The development of vestibuloocular circuitry in the chicken embryo. J Physiol (Paris) 97:17-25.

Glover JC, Petursdottir G (1991): Regional specificity of developing reticulospinal, vestibulospinal and vestibulo-ocular projections in the chicken embryo. J Neurobiol 22:353-376.

Goldberg JM (2000): Afferent diversity and the organization of central vestibular pathways. Exp Brain Res 130:277-297.

Grocott T, Tambalo M, Streit A (2012): The peripheral sensory nervous system in the vertebrate head: a gene regulatory perspective. Dev Biol 370:3-23.
Hammond KL, Whitfield TT (2006): The developing lamprey ear closely resembles the zebrafish otic vesicle: Otx1 expression can account for all major patterning differences. Development 133:1347-1357.

Hill A, Boll W, Ries C, Warner L, Osswalt M, Hill M, Noll M (2010): Origin of Pax and Six gene families in sponges: single PaxB and Six $1 / 2$ orthologs in Chalinula loosanoffi. Dev Biol 343:106-123.

-Hwang CH, Simeone A, Lai E, Wu DK (2009): Foxg1 is required for proper separation and formation of sensory cristae during inner ear development. Dev Dyn 238:2725-2734.

-Jahan I, Kersigo J, Pan N, Fritzsch B (2010): Neurod1 regulates survival and formation of connections in mouse ear and brain. Cell Tissue Res 341:95-110.

- Joyce Tang W, Chen JS, Zeller RW (2013): Transcriptional regulation of the peripheral nervous system in Ciona intestinalis. Dev Biol 378:183-193.

Kaminski HJ, Richmonds CR, Kusner LL, Mitsumoto H (2002): Differential susceptibility of the ocular motor system to disease. Ann NY Acad Sci 956:42-54

Kopecky B, Santi P, Johnson S, Schmitz H, Fritzsch B (2011): Conditional deletion of NMyc disrupts neurosensory and non-sensory development of the ear. Dev Dyn 240:13731390.

Kozmik Z, Daube M, Frei E, Norman B, Kos L, Dishaw LJ, Noll M, Piatigorsky J (2003): Role of Pax genes in eye evolution: a cnidarian PaxB gene uniting Pax2 and Pax6 functions. Dev Cell 5:773-785.

Lamb TD (2013): Evolution of phototransduction, vertebrate photoreceptors and retina. Prog Retin Eye Res 36:52-119.

-Lambert FM, Beck JC, Baker R, Straka H (2008): Semicircular canal size determines the developmental onset of angular vestibuloocular reflexes in larval Xenopus. J Neurosci 28:80868095.

Lambert FM, Combes D, Simmers J, Straka H (2012): Gaze stabilization by efference copy signaling without sensory feedback during vertebrate locomotion. Curr Biol 22:16491658.

Lewis ER, Leverenz EL, Bialek WS (1985): The Vertebrate Inner Ear. Boca Raton, CRC Press.

Lorente de Nó R (1933): Vestibulo-ocular reflex arc. Arch Neurol Psychiatry 30:245-291.

Maklad A, Fritzsch B (2002): The developmental segregation of posterior crista and saccular vestibular fibers in mice: a carbocyanine tracer study using confocal microscopy. Brain Res Dev Brain Res 135:1-17.

Maklad A, Fritzsch B (2003a): Partial segregation of posterior crista and saccular fibers to the nodulus and uvula of the cerebellum in mice, and its development. Brain Res Dev Brain Res 140:223-236.

Maklad A, Fritzsch B (2003b): Development of vestibular afferent projections into the hindbrain and their central targets. Brain Res Bull 60:497-510. 
-Maklad A, Kamel S, Wong E, Fritzsch B (2010): Development and organization of polarityspecific segregation of primary vestibular afferent fibers in mice. Cell Tissue Res 340:303321.

Markl H (1974): The perception of gravity and of angular acceleration in invertebrates; in Kornhuber HH (ed): Handbook of Sensory Physiology: vol VI/1 Vestibular System. Berlin, Springer, pp 17-74.

Mazan S, Jaillard D, Baratte B, Janvier P (2000): Otxl gene-controlled morphogenesis of the horizontal semicircular canal and the origin of the gnathostome characteristics. Evol Dev 2:186-193.

-Murakami Y, Pasqualetti M, Takio Y, Hirano S, Rijli FM, Kuratani S (2004): Segmental development of reticulospinal and branchiomotor neurons in lamprey: insights into the evolution of the vertebrate hindbrain. Development 131:983-995.

- Nichols DH, Pauley S, Jahan I, Beisel KW, Millen KJ, Fritzsch B (2008): Lmxla is required for segregation of sensory epithelia and normal ear histogenesis and morphogenesis. Cell Tissue Res 334:339-358.

- Nolte C, Krumlauf R (2006): Expression of Hox genes in the nervous system of vertebrates; in Papageorgiou S (ed): Hox Gene Expression. Austin, Landes Bioscience \& Springer, pp 1441.

Pan N, Kopecky B, Jahan I, Fritzsch B (2012): Understanding the evolution and development of neurosensory transcription factors of the ear to enhance therapeutic translation. Cell Tissue Res 349:415-432.

-Pani AM, Mullarkey EE, Aronowicz J, Assimacopoulos S, Grove EA, Lowe CJ (2012): Ancient deuterostome origins of vertebrate brain signalling centres. Nature 483:289-294.

- Pasqualetti M, Díaz C, Renaud JS, Rijli F, Glover JC (2007): Fate-mapping the mammalian hindbrain: segmental origins of vestibular projection neurons assessed using rhombomere-specific Hoxa2 enhancer elements in the mouse embryo. J Neurosci 27:9670-9681.

-Pauley S, Lai E, Fritzsch B (2006): Foxg1 is required for morphogenesis and histogenesis of the mammalian inner ear. Dev Dyn 235: 2470-2482.

-Pflieger JF, Dubuc R (2004): Vestibulo-reticular projections in adult lamprey: their role in locomotion. Neuroscience 129:817-829.

- Pierce ML, Weston MD, Fritzsch B, Gabel HW, Ruvkun G, Soukup GA (2008): MicroRNA-183 family conservation and ciliated neurosensory organ expression. Evol Dev 10: 106-113.

Prince VE, Price AL, Ho RK (1998): Hox gene expression reveals regionalization along the anteroposterior axis of the zebrafish notochord. Dev Genes Evol 208:517-522.

-Puelles L (1978): A Golgi-study of oculomotor neuroblasts migrating across the midline in chick embryos. Anat Embryol (Berl) 152:205215.
Puzdrowski RL (1998): Innervation of the medial rectus muscle in the ratfish, Hydrolagus colliei. J Comp Neurol 400:571-579.

- Rota-Stabelli O, Campbell L, Brinkmann H, Edgecombe GD, Longhorn SJ, Peterson KJ, Pisani D, Philippe H, Telford MJ (2011): A congruent solution to arthropod phylogeny: phylogenomics, microRNAs and morphology support monophyletic Mandibulata. Proc Biol Sci 278:298-306.

Rubel EW, Fritzsch B (2002): Auditory system development: primary auditory neurons and their targets. Annu Rev Neurosci 25:51-101.

Simpson JI, Graf W (1985): The selection of reference frames by nature and its investigators; in Berthoz A, Melvill Jones G (eds): Adaptive Mechanisms in Gaze Control: Facts and Theories. Amsterdam, Elsevier, pp 3-16.

- Soukup GA, Fritzsch B, Pierce ML, Weston MD, Jahan I, McManus MT, Harfe BD (2009): Residual microRNA expression dictates the extent of inner ear development in conditional Dicer knockout mice. Dev Biol 328:328-341.

Straka H, Biesdorf S, Dieringer N (1997): Canalspecific excitation and inhibition of frog second order vestibular neurons. J Neurophysiol 78:1363-1372.

Straka H (2010): Ontogenetic rules and constraints of vestibulo-ocular reflex development. Curr Opin Neurobiol 20:689-695.

-Straka H, Baker R (2013): Vestibular blueprint in early vertebrates. Front Neural Circuits 7:182.

Straka H, Baker R, Gilland E (2001): Rhombomeric organization of vestibular pathways in larval frogs. J Comp Neurol 437:42-55.

-Straka H, Baker R, Gilland E (2002a): The frog as a unique vertebrate model for studying the rhombomeric organization of functionally identified hindbrain neurons. Brain Res Bull 57:301-305.

Straka H, Beraneck M, Rohregger M, Moore LE, Vidal PP, Vibert N (2004): Second-order vestibular neurons form separate populations with different membrane and discharge properties. J Neurophysiol 92:845-861.

Straka H, Dieringer N (2004): Basic organization principles of the VOR: lessons from frogs. Prog Neurobiol 73:259-309.

-Straka H, Holler S, Goto F (2002b): Patterns of canal and otolith afferent input convergence in frog second order vestibular neurons. J Neurophysiol 88:2287-2301.

-Straka H, Holler S, Goto F, Kolb FP, Gilland E (2003): Differential spatial organization of otolith signals in frog vestibular nuclei. J Neurophysiol 90:3501-3512.

- Straka H, Lambert FM, Pfanzelt S, Beraneck M (2009): Vestibulo-ocular signal transformation in frequency-tuned channels. Ann NY Acad Sci 1164:37-44.

Straka H, Vibert N, Vidal PP, Moore LE, Dutia MB (2005): Intrinsic membrane properties of vertebrate vestibular neurons: function, development and plasticity. Prog Neurobiol 76: 349-392.
Streit A (2007): The preplacodal region: an ectodermal domain with multipotential progenitors that contribute to sense organs and cranial sensory ganglia. Int J Dev Biol 51:447461.

Suwa H, Gilland E, Baker R (1996): Segmental organization of vestibular and reticular projections to spinal and oculomotor nuclei in the zebrafish and goldfish. Biol Bull 191:257-259.

-Szentagothai J (1950): The elementary vestibuloocular reflex arc. J Neurophysiol 13:395-407.

Tischfield MA, Baris HN, Wu C, Rudolph G, Van Maldergem L, He W, Chan WM, Andrews C, Demer JL, Robertson RL, Mackey DA, Ruddle JB, Bird TD, Gottlob I, Pieh C, Traboulsi EI, Pomeroy SL, Hunter DG, Soul JS, Newlin A, Sabol LJ, Doherty EJ, de Uzcategui CE, de Uzcategui N, Collins ML, Sener EC, Wabbels B, Hellebrand $\mathrm{H}$, Meitinger T, de Berardinis T, Magli A, Schiavi C, Pastore-Trossello M, Koc F, Wong AM, Levin AV, Geraghty MT, Descartes M, Flaherty M, Jamieson RV, Moller HU, Meuthen I, Callen DF, Kerwin J, Lindsay S, Meindl A, Gupta ML Jr, Pellman D, Engle EC (2010): Human TUBB3 mutations perturb microtubule dynamics, kinesin interactions, and axon guidance. Cell 140:74-87.

- Trinajstic K, Sanchez S, Dupret V, Tafforeau P, Long J, Young G, Senden T, Boisvert C, Power N, Ahlberg PE (2013): Fossil musculature of the most primitive jawed vertebrates. Science 341:160-164.

Uchino Y, Ikegami H, Sasaki M, Endo K, Imagawa M, Isu N (1994): Monosynaptic and disynaptic connections in the utriculo-ocular reflex arc of the cat. J Neurophysiol 71:950-958.

Uchino Y, Sasaki M, Sato H, Imagawa M, Suwa H, Isu N (1996): Utriculoocular reflex arc of the cat. J Neurophysiol 76:1896-1903.

Vaage S (1969): The segmentation of the primitive neural tube in chick embryos (Gallus domesticus). A morphological, histochemical and autoradiographical investigation. Ergeb Anat Entwicklungsgesch 41:3-87.

von Uckermann G, Le Ray D, Combes D, Straka H, Simmers J (2013): Spinal efference copy signaling and gaze stabilization during locomotion in juvenile Xenopus frogs. J Neurosci 33:4253-4264.

Vopalensky P, Pergner J, Liegertova M, BenitoGutierrez E, Arendt D, Kozmik Z (2012): Molecular analysis of the amphioxus frontal eye unravels the evolutionary origin of the retina and pigment cells of the vertebrate eye. Proc Natl Acad Sci USA 109:15383-15388.

-Wada H (1998) Evolutionary history of freeswimming and sessile lifestyles in urochordates as deduced from $18 \mathrm{~S}$ rDNA molecular phylogeny. Mol Biol Evol 15:1189-1194.

-Wahl CM, Noden DM, Baker R (1994): Developmental relations between sixth nerve motor neurons and their targets in the chick embryo. Dev Dyn 201:191-202.

Young GC (2008): Number and arrangement of extraocular muscles in primitive gnathostomes: evidence from extinct placoderm fishes. Biol Lett 4:110-114. 